\title{
Acid Cleaning of Corrosive Kraft Digesters and Evaporators
}

\author{
Moses Wekesa ${ }^{1}$, Md. Jamal Uddin ${ }^{1, *}$, Pablo Conde ${ }^{2}$, Preet Singh ${ }^{2}$ \\ ${ }^{1}$ Coppin State University, Department of Natural Sciences, Baltimore, MD, USA \\ ${ }^{2}$ Georgia Institute of Technology, Institute of Pulp and Paper Science \& Technology, Atlanta, USA \\ *Corresponding Author: juddin@coppin.edu
}

Copyright (C) 2014 Horizon Research Publishing All rights reserved.

\begin{abstract}
During scheduled shut downs of $\mathrm{Kraft}$ evaporator and digester, acid cleaning is required to remove scales that precipitate from chemical species present in liquors. Acid cleaning can affect the base metal of the Kraft equipment leading to significant localized corrosion, which can lead to unexpected failures. Burkeite was deposited on the carbon steel coupons and the x-ray diffractometer pattern of the scale was taken. $20 \%$ sulfamic acid solution with $0.5 \%$ inhibitor $\mathrm{B}$ was found to be effective in scale removal at either $25^{\circ} \mathrm{C}$ or $50^{\circ} \mathrm{C}$. The rate of scale removal increased by either increasing the temperature or the rate of stirring (flow rate). Also changing the scale morphology was another way of enhancing its removal.
\end{abstract}

Keywords Kraft Equipment, Sulfamic Acid, Inhibitor, $\mathrm{NH}_{2} \mathrm{SO}_{3} \mathrm{H}$

\section{Introduction}

In North American paper mills aqueous spent liquor from Kraft digesters is concentrated in multiple-effect evaporators. The concentrated liquor is then burned to recover energy and regenerate pulping chemicals. Some of the constituents of the black liquor are carbonate compounds. Carbonate compounds have reverse solubility and precipitate out as the temperature increases. Hence, during evaporation stage, as the solvent is continuously removed, crystals of sodium salts and calcium that are produced and form scales on the heat transfer surfaces. The presence of such scales may not be harmful from the corrosion point of view however their removal may affect the base metal where they grow on. Also, scale formation reduces through puts leading to increased pumping costs. Multiple -effect evaporators with tube heating elements [falling film or long-tube vertical (LTV) evaporator bodies] are susceptible to plugging on the onset of scaling. Heating or cooling requirements are also increased because of the lowering flow rates, heat transfer coefficients, and by the increased pressure drops [2].

Most of the composition of the scale in the kraft evaporators and digesters is burkeite and calcium carbonate. Burkeite is a soluble double salt of sodium carbonate and sodium sulfate crystallizes out when the black liquor is $50 \%$ total solid content [3]. In paper mills it is normally removed by hot water. Calcium carbonate is the insoluble part of the scale. Calcium carbonate precipitates out in different forms depending on temperature and the most common forms are: aragonite, calcite and vaterite. The precipitation of $\mathrm{CaCO}_{3}$ is as follows:

$$
\begin{gathered}
2 \mathrm{HCO}_{3}{ }^{-} \leftrightarrow \mathrm{CO}_{2} \text { (dissolved) }+\mathrm{CO}_{3}{ }^{2-}+\mathrm{H}_{2} \mathrm{O} \\
\mathrm{Ca}^{2+}+\mathrm{CO}_{3}{ }^{2-} \rightarrow \mathrm{CaCO}_{3}(\mathrm{~s})
\end{gathered}
$$

Although most cleaning for pulping equipment is performed with inhibited muriatic acid $(\mathrm{HCl})$, other acids such as sulfamic acid, formic acid and nitric acid have been used [4]. Acid concentration, inhibitor, temperature, time and flow rates are important parameters that will establish well-defined procedures to minimize damage to the equipment. Despite the relevance of such procedures to the pulp and paper industry, very little published work has addressed the problems faced during acid cleaning.

Acid cleaning of kraft digesters is required on regular basis to remove carbonate scale deposits. Corrosion concerns with acid cleaning of kraft equipment have been discussed by Henrikson [5]. Significant corrosion damage to kraft equipment has occurred due to mistakes in acid cleaning. Crowe [4] investigated corrosion behavior of acid cleaning solutions via laboratory tests of hydrochloric acid, formic acid, sulfamic acid and nitric acids. He confirmed the risk of pitting or cracking stainless steel when cleaning with hydrochloric acid. Perdomo et al. [6] have studied corrosion prevention during acid cleaning in digesters and evaporators and concluded that $20 \%$ inhibited sulfamic acid and 5\% inhibited hydrochloric acid can minimize corrosion rate and there is no evidence of stress corrosion cracking. They also observed that acid cleaning efficiencies are $80 \%$ or better for the inhibited sulfamic acid and hydrochloric acid.

In general corrosion rate increase with acid concentration, and temperature. In the case of carbon steel, most acids will dissolve base metal at corrosion rates beyond 100 mpy [7]. Despite the use of corrosion inhibitors, the metallurgical 
damage associated with acid cleaning is reflected in the form of pitting corrosion regardless of steel type, end-grain corrosion of stainless steels (SS) and ferrite attack in welds [7-9]. The objective of this study was to make scales (burkeite and calcium carbonate) typical of those found in evaporators and digesters and use optimized conditions of sulfamic acid and hydrochloric acid to remove the scales.

\section{Experimental}

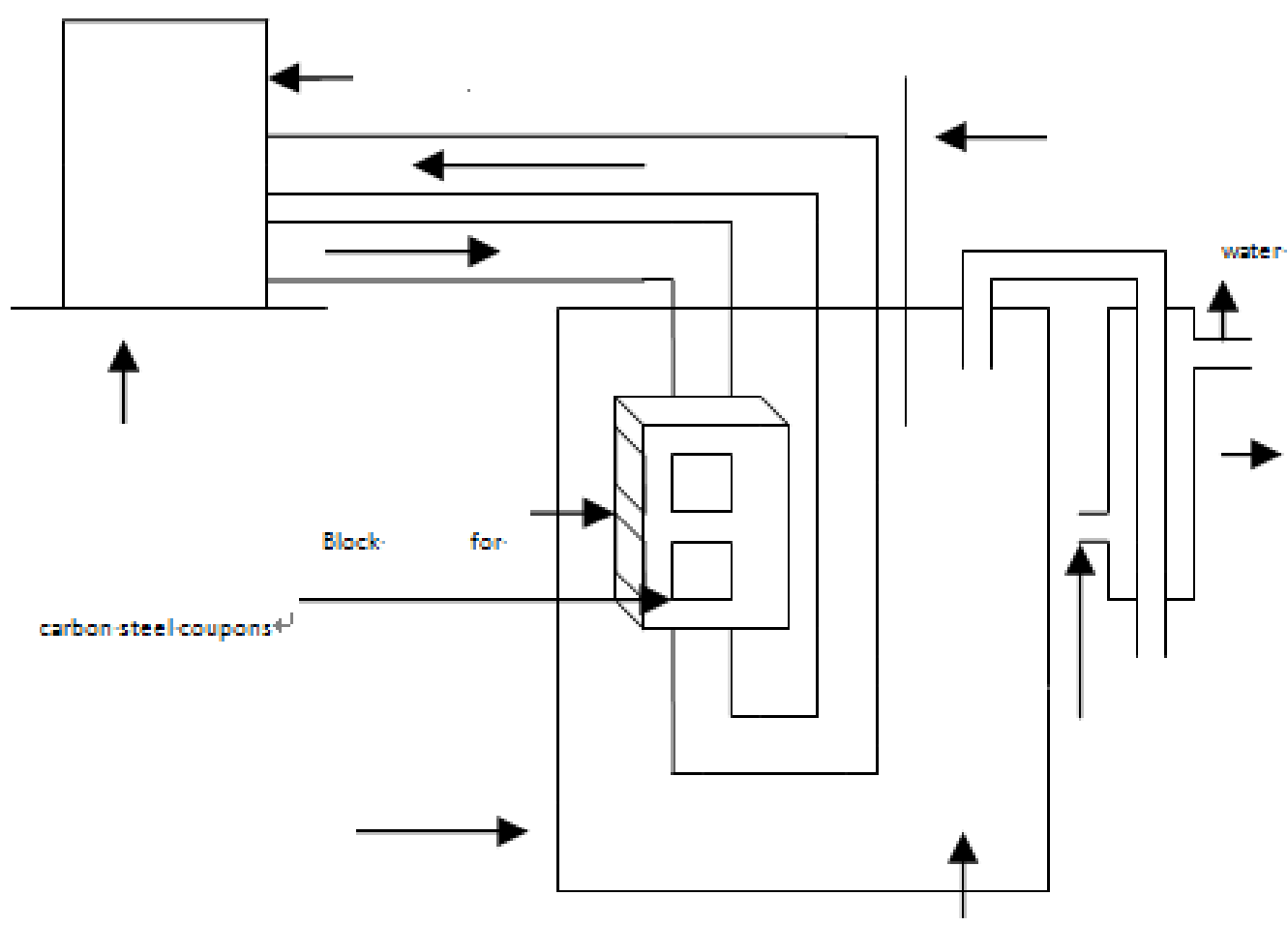

Figure 1. Shematic diagram of eperimental set up

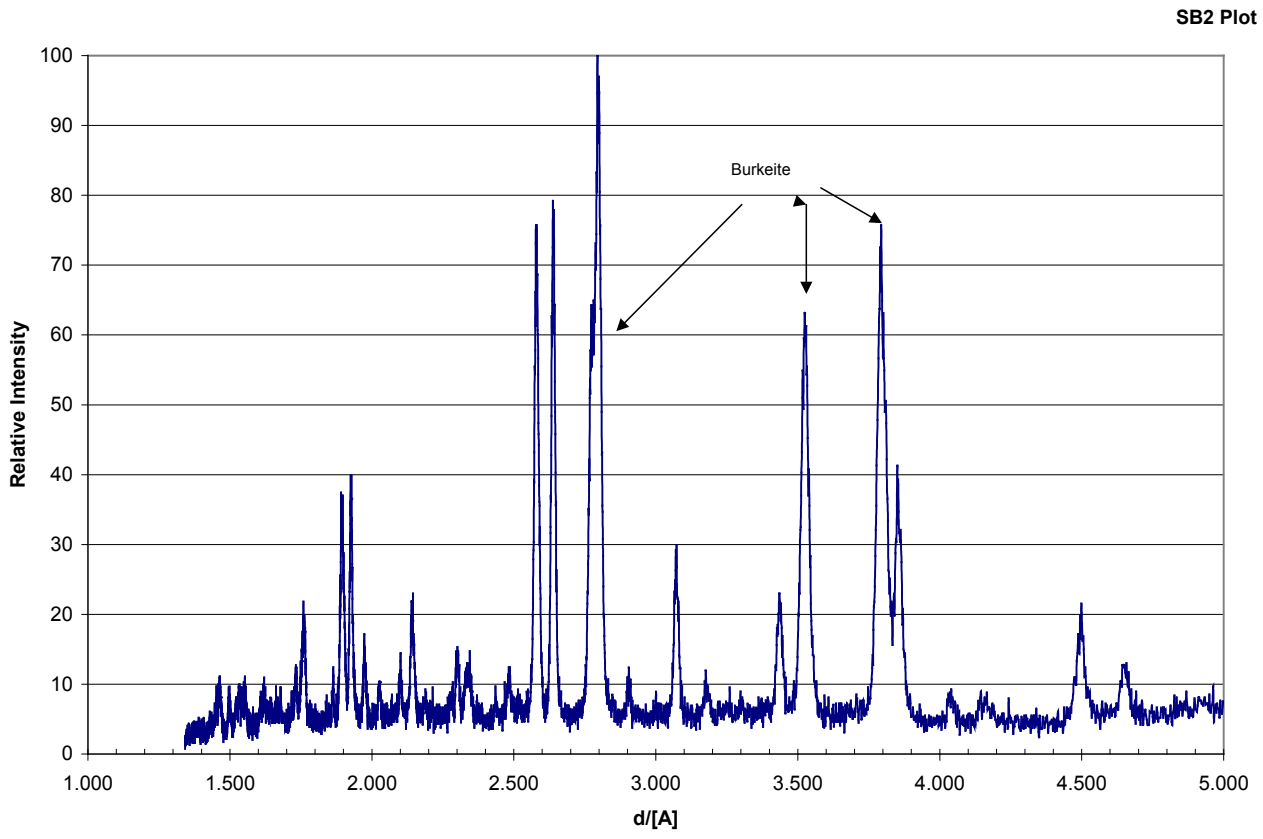

Figure 2. X-ray chromatogram of the burkeite scale. 


\section{Scale Deposition}

Scales with different compositions typically found in evaporators were deposited on carbon steel coupons. The heat exchanger was built in the lab to simulate evaporator conditions. A 3.5 L Autoclave reactor was used. A special heat exchanger was designed with a flat section in it where carbon steel coupons could be attached. The samples were pre-weighed prior to the test. Hot water at $100^{\circ} \mathrm{C}$ was circulated through the closed hot heat exchanger submerged in the solution saturated with the scaling chemicals for $72 \mathrm{hrs}$. The scaling chemicals were prepared from commercially available A.C.S. grade salts $\left(\mathrm{Na}_{2} \mathrm{SO}_{4}\right.$ and $\left.\mathrm{Na}_{2} \mathrm{CO}_{3}\right)$ in $2.5 \mathrm{~L}$ distilled water to produce a solution with $43 \%$ mass by weight. The $\mathrm{Na}_{2} \mathrm{CO}_{3}$ to $\mathrm{Na}_{2} \mathrm{SO}_{4}$ mole ratio was fixed at 2:6 to achieve Burkeite scale composition. The schematic of experimental set up is shown in Figure 1. At the end of each test, the carbon steel coupons with the deposited scale were removed, air-dried overnight and re-weighed. The difference in weight of the carbon steel coupons with and without the scale was taken as the weight of the scale. The scale was characterized and confirmed to be Burkeite by $\mathrm{x}$-ray diffract meter as shown in Figure 2.

The same procedure was followed for the formation of $\mathrm{CaCO}_{3}$ scale except that the chemicals used were $\mathrm{Na}_{2} \mathrm{CO}_{3}$ and $\mathrm{CaCl}_{2}$. The scale was characterized and confirmed to be $\mathrm{CaCO}_{3}$ by x-ray diffractometer as shown in Figure 6.

\section{Acid Cleaning}

Hot plate connected to thermocouple was used for heating purposes. The electric stirrer was used to continuously mix the solution. Cleaning acids used in this study include 5\% hydrochloric acid $(\mathrm{HCl})$ solution and $20 \%$ sulfamic acid. All reagents were analytical grade. Distilled water was used to serve as a control. Rodine 213 (inhibitor A) and Rodine 31A (inhibitor B) were industrial grade, and their compositions were proprietary to the suppliers. Inhibitors were added to the solution as volume percent based on the volume of the acid plus water. The coupon surface to cleaning solution ratio, $\mathrm{S} / \mathrm{V}$, was $\approx 0.01 \mathrm{~cm}^{-1}$, which simulated the surface to volume ratio typically found in the field $\mathrm{S} / \mathrm{V}$ for the digester. Samples were suspended in the solution by the magnetic rod for a specified period of time after which they were removed, dried and weighed. The difference in weight between the initial weight of the coupon with scale and the final weight of the coupon with scale was taken as the loss in weight of the scale. The flow rate was fixed at $500 \mathrm{rev} / \mathrm{min}$ for normal stir and $1000 \mathrm{rev} / \mathrm{min}$ for fast stir.

\section{Results and Discussion}

Burkeite is less soluble in water at high temperature and therefore, by passing hot water in the tube submerged in the saturated solution of $\mathrm{Na}_{2} \mathrm{CO}_{3}$ and $\mathrm{Na}_{2} \mathrm{SO}_{4}$, scale was deposited on the heat exchanger tube which is similar to the scale deposition in the evaporators and digesters. The x-ray diffractometer pattern of the scale had three peaks at 2.81 , 3.53 and 3.80. These three peaks indicated in Figure 2 confirmed that the scale deposited on the heat exchanger was burkeite. Acid cleaning tests on the scale were then carried out using $\mathrm{NH}_{2} \mathrm{SO}_{3} \mathrm{H}$ and $\mathrm{HCl}$. Some tests were carried out with distilled de-ionized water to establish the base line.

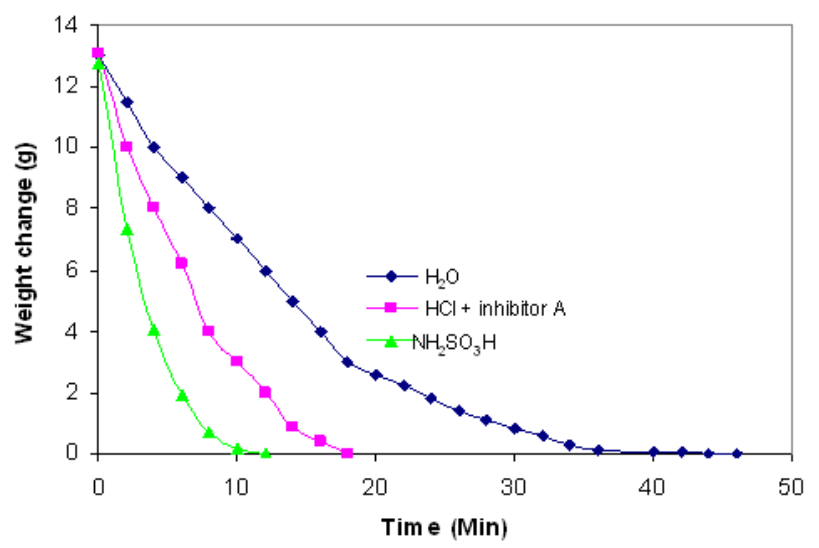

Figure 3. Loss of scale as a function of time ( $5 \% \mathrm{HCI}, 20 \% \mathrm{NH}_{2} \mathrm{SO}_{3} \mathrm{H}, 2 \%$ inhibitor $\mathrm{A}, 0.5 \%$ inhibitor $\mathrm{B}, 25^{\circ} \mathrm{C}$

Figure 3, presents weight change of scale with time at room temperature. It was found that $\mathrm{NH}_{2} \mathrm{SO}_{3} \mathrm{H}$ with inhibitor B was better at scale removal than $\mathrm{HCl} \& \mathrm{H}_{2} \mathrm{O}$. As expected $\mathrm{H}_{2} \mathrm{O}$ was the least in terms of scale removal. This is not surprising because $\mathrm{NH}_{2} \mathrm{SO}_{3} \mathrm{H}$ and $\mathrm{HCl}$ remove scale by chemical reaction. Possible chemical reactions are:

$$
\begin{gathered}
2 \mathrm{Na}_{2} \mathrm{CO}_{3} \cdot \mathrm{Na}_{2} \mathrm{SO}_{4}+4 \mathrm{HCl} \rightarrow 2 \mathrm{CO}_{2(\mathrm{~g})}+4 \mathrm{NaCl}_{(\mathrm{ag})}+2 \mathrm{H}_{2} \mathrm{O}_{(\mathrm{l})}+\mathrm{Na}_{2} \mathrm{SO}_{4(\mathrm{ag})} \\
\left.2 \mathrm{Na}_{2} \mathrm{CO}_{3} \cdot \mathrm{Na}_{2} \mathrm{SO}_{4}+4 \mathrm{NH}_{2} \mathrm{SO}_{3} \mathrm{H} \rightarrow 2 \mathrm{CO}_{2(\mathrm{~g}}\right)+\mathrm{Na}_{2} \mathrm{SO}_{4(\mathrm{ag})}+2 \mathrm{H}_{2} \mathrm{O}_{(\mathrm{l})}+4 \mathrm{NH}_{2} \mathrm{SO}_{3} \mathrm{Na}_{(\mathrm{aq})} \\
2 \mathrm{Na}_{2} \mathrm{CO}_{3} \cdot \mathrm{Na}_{2} \mathrm{SO}_{4}+4 \mathrm{NH}_{2} \mathrm{SO}_{3} \mathrm{H} \rightarrow 2 \mathrm{CO}_{2(\mathrm{~g})}+\mathrm{Na}_{2} \mathrm{SO}_{4(\mathrm{ag})}+2 \mathrm{H}_{2} \mathrm{O}_{(\mathrm{l})}+2 \mathrm{~N}_{2}+4 \mathrm{H}_{2} \mathrm{SO}_{3} \mathrm{Na}(\mathrm{aq}) \\
2 \mathrm{Na}_{2} \mathrm{CO}_{3} \cdot \mathrm{Na}_{2} \mathrm{SO}_{4}+4 \mathrm{NH}_{2} \mathrm{SO}_{3} \mathrm{H} \rightarrow 2 \mathrm{CO}_{2(\mathrm{~g})}+\mathrm{Na}_{2} \mathrm{SO}_{4(\mathrm{ag})}+2 \mathrm{H}_{2} \mathrm{O}_{(\mathrm{l})}+2 \mathrm{~N}_{2}+4 \mathrm{H}_{2} \mathrm{SO}_{3} \mathrm{Na}(\mathrm{aq}) \\
4 \mathrm{H}_{2} \mathrm{SO}_{3} \mathrm{Na}_{(\mathrm{aq})}+4 \mathrm{H}_{2} \mathrm{O} \rightarrow 4 \mathrm{NaHSO}_{4}+7 \mathrm{H}_{2} \\
4 \mathrm{NaHSO}_{4} \rightarrow \mathrm{Na}_{2} \mathrm{SO}_{4(\mathrm{ag})}+\mathrm{H}_{2} \mathrm{SO}_{4(\mathrm{ag})}
\end{gathered}
$$

Since most reactions are affected by temperature, we tried the same experiments at $50^{\circ} \mathrm{C}$ and results are given in Figure 4 . 


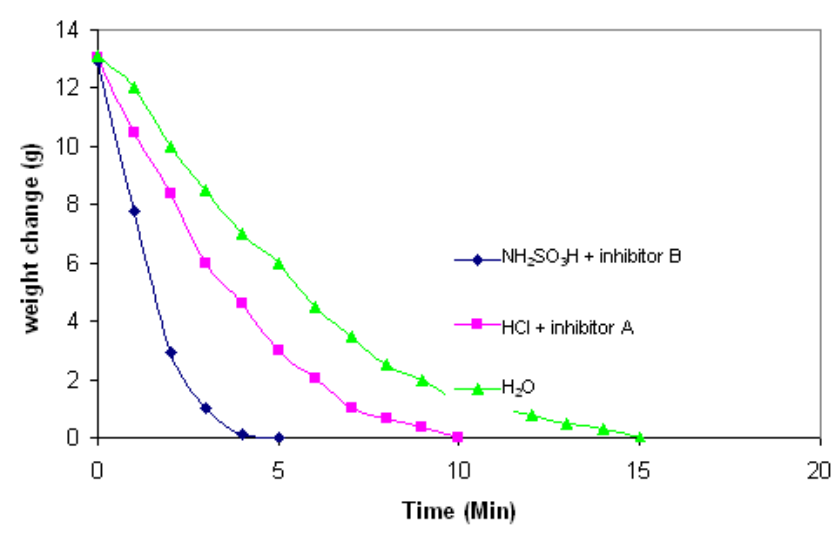

Figure 4. The weight change of burkeite at increased temperature $\left(5 \% \mathrm{HCI}, 20 \% \mathrm{NH}_{2} \mathrm{SO}_{3} \mathrm{H}, 2 \%\right.$ inhibitor $\mathrm{A}, 0.5 \%$ inhibitor $\mathrm{B}, \mathrm{T}, 50^{\circ} \mathrm{C}$

By increasing the temperature from $25^{\circ} \mathrm{C}$ to $50^{\circ} \mathrm{C}$, the rate of scale for the three runs increased. This observation is due to increase in the kinetics of dissolution reactions involved.

Figure 5 presents the effect of the surface area and rate of stirring on the loss in weight of the scale. By removing the scale from the coupon and grinding into powder the surface area is increased. Under this condition it was found that the rate of loss of weight in scale also increased. By increasing the rate of stirring, the rate of dissolution reaction increased as shown in Figure 5. Hence, scale removal can be enhanced by changing the flow rate and scale morphology.

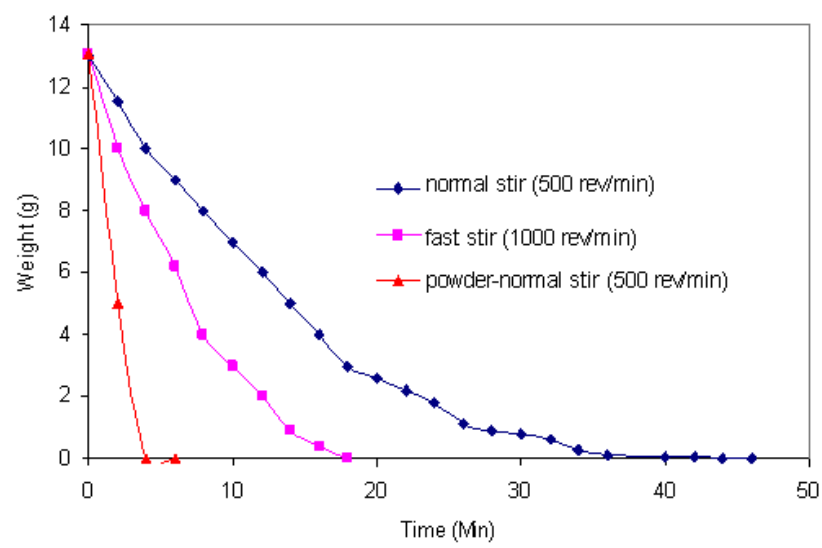

Figure 5. Effect of stirring \& surface area on dissolution of burkeite $\left(\mathrm{H}_{2} \mathrm{O}, 25^{\circ} \mathrm{c}\right)$

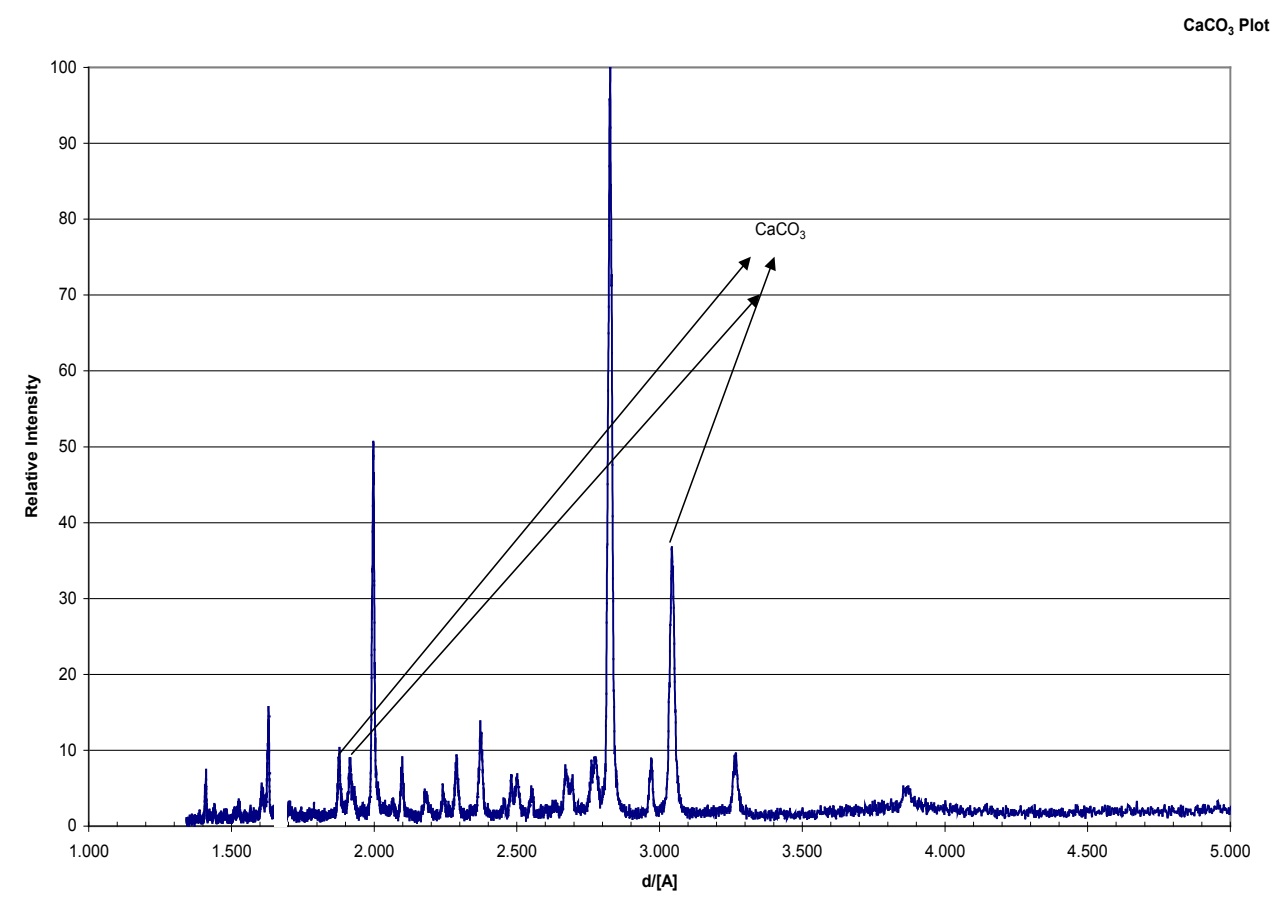

Figure 6. X-ray chromatogram of calcium carbonate scale

Figure 6 presents the x-ray pattern of calcium carbonate scale. The peaks at 1.87, 1.91 and 3.04 confirm the presence of calcium carbonate in the scale. Tests on $\mathrm{CaCO}_{3}$ scale were then carried out at room temperature and 50oC. Figure 7 presents $\mathrm{CaCO}_{3}$ scale removal at $25 \mathrm{oC}$. 


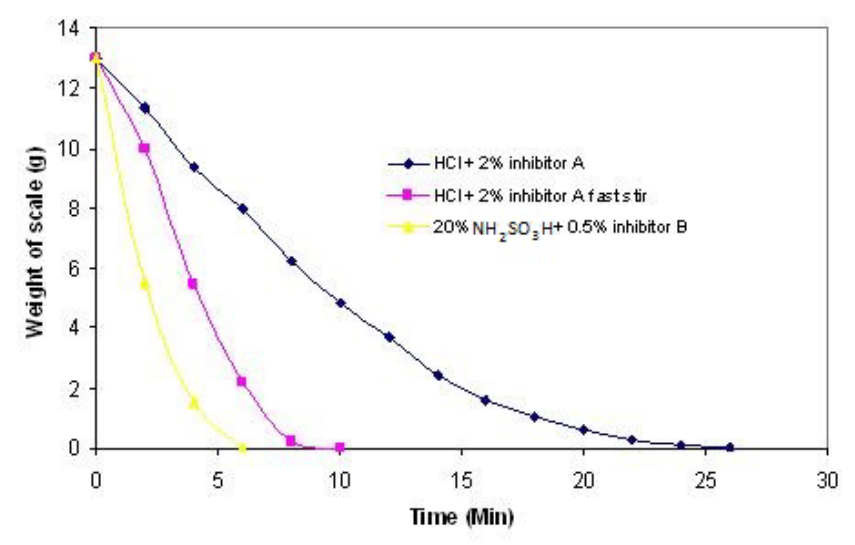

Figure 7. Weight of calcium carbonate scale as a function of time (HCI, $5 \%$, $\mathrm{NH}_{2} \mathrm{SO}_{3} \mathrm{H}, 20 \%$, inhibitor $\mathrm{A}, 2 \%$ inhibitor $\mathrm{A}, 2 \%$ inhibitor $\mathrm{B}, 0.5 \%, \mathrm{~T}, 25^{\circ} \mathrm{c}$

Hydrochloric acid solution takes about $26 \mathrm{~min}$ to dissolve about $13 \mathrm{~g}$ of the deposited scale, while $\mathrm{NH}_{2} \mathrm{SO}_{3} \mathrm{H}$ acid solution takes only $6 \mathrm{~min}$. By increasing the flow rate or speed of stirring, the rate of $\mathrm{CaCO}_{3}$ scale dissolution is expected to increase. This is confirmed in this figure with $\mathrm{HCl}$ acid solution. By doubling the rate of stir the time taken for the same amount of scale to be removed is reduced to 10 min, which is equivalent to the increase in removal rate by over $140 \%$.

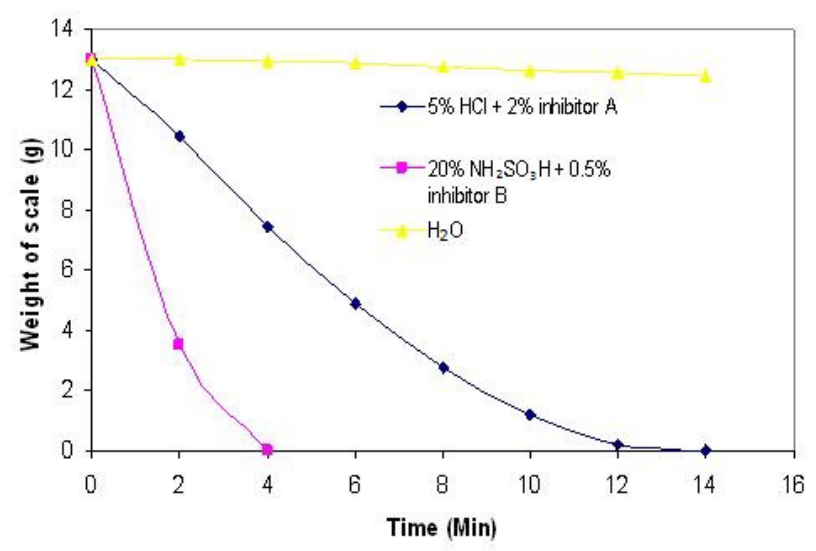

Figure 8. Weight of calcium carbonate as a function of time (HCI, 5\%, $\mathrm{NH}_{2} \mathrm{SO}_{3} \mathrm{H}$, inhibitor $\mathrm{A}, 2 \%$, inhibitor $\mathrm{B}, 0.5 \%, \mathrm{~T}, 50^{\circ} \mathrm{c}$ )

Figure 8 presents $\mathrm{CaCO}_{3}$ scale removal at increased temperature. By increasing the temperature it is expected that the kinetics of scale removal are going to change. This is confirmed in this figure. By increasing the temperature from $25^{\circ} \mathrm{C}$ to $50^{\circ} \mathrm{C}$, the time needed to remove the same amount of scale for sulfamic acid reduces from 6 min to less than $4 \mathrm{~min}$; this is equivalent to $50 \%$ increase in the rate of removal. For $\mathrm{HCl}$ increasing the temperature reduces the time for scale removal for the same amount of scale from $26 \mathrm{~min}$ to $14 \mathrm{~min}$, which is equivalent to $85 \%$ of the increase in the rate of scale removal. Finally, $\mathrm{H}_{2} \mathrm{O}$ was used to dissolve the scale. Since $\mathrm{CaCO}_{3}$ scale insoluble it did not dissolve, which is expected because $\mathrm{CaCO}_{3}$ is insoluble in water.

\section{Conclusion}

$20 \%$ sulfamic acid solution with $0.5 \%$ inhibitor B has been found to be effective in scale removal at either $25^{\circ} \mathrm{C}$ or $50^{\circ} \mathrm{C}$. The rate of scale removal can be increased by either increasing the temperature or the rate of stirring (flow rate). Also changing the scale morphology is another way of enhancing its removal.

\section{REFERENCES}

[1] Rosier, M.A., "Model to predict the precipitation of burkeite in the multiple-effect evaporator and techniques for controlling scaling", Tappi J., 80(4)203-209 (1997).

[2] Atkinson, C., Heybourne, M.J.H., IIey, W.J., Russel, P.C., Taylor, T., and Jones, D.P., "Powder for use as a Granular Detergent Composition-Obtained from Sodium Carbonate and Sodium Sulfate Using a Crystal Growth Modifier", European Patent EP221776A, 1987.

[3] Euhus, D.D., Shi, B., Rousseau, R.W., "Control of Soluble Scale in Black Liquor Evaporators and Concentrators: Part 1. Pilot Plant Studies", Tappi Fall Conference and trade Fair", (2002).

[4] Crowe, C.C., "Corrosion in Acid Cleaning Solutions for Kraft Digesters", $7^{\text {th }}$ International Symposium on Corrosion in the Pulp and Paper Industry, Tappi, Orlando, FL, pp33-40, (1992).

[5] Hendrickson, S., Svensk Papperstid., 86(3):184-187, (1983).

[6] Perdomo, J.J., Singh, P.M., Conde, P., Mahmood, J., "Corrosion During Acid Cleaning of Kraft Digesters and Evaporators", unpublished report.

[7] ASTM G1-90(1999), "Preparing, Cleaning and Evaluating Corrosion Test Specimens", ASTM Book of Standards, West Conshohocken, PA, 03.02, pp5, (2001).

[8] ASTM G 48- 00, "Pitting and Crevice Corrosion Resistance of Stainless Steels and Related Alloys by the Use of Ferric Chloride Solution", ASTM Book of Standards, West Conshohocken, PA, 03.02, pp181, (2002).

[9] ASTM G 58- 85(1999), "Preparation of Stress Corrosion Test Specimens for Weldments", ASTM Book of Standards, West Conshohocken, PA, 03.02, pp265, (2002). 